\title{
Using two tools movement in incremental forming process by finite element analysis
}

\author{
Khalil Ibrahim Abass* \\ Al Mustansiriyah University, Engineering Collage, Mechanical Engineering Department, Baghdad, Iraq
}

\begin{abstract}
Single Point Incremental Forming, SPIF and Two Point Incremental Forming, TPIF are two types of Incremental Sheet Forming ISF processes with high economic potential payoff for rapid prototyping applications. The process requires a $\mathrm{CNC}$ machining centre, a spherical tip tool and a simple support to fix the workpiece. The process is more complicated by highly nonlinear boundary conditions, namely contact and frictional effects. However, this process, numerical approach, dominated by the Finite Element Method, FEM is being used. The paper presents the data and main results of a study on the effect of using two forming tool movements through FE analysis. The certain process conditions referring to the test blank, tool, etc., applying ANSYS application program. The results show that the upper TPIF process is more stable during the deformation process steps by chattering statuses evaluation and improve the strain distributions of the deformed blank.
\end{abstract}

\section{Introduction}

The advanced Incremental Sheet Forming or ISF process includes the local (point) deformation of the blank sheet by using a simple geometry (spherical or hemispherical) tooling system [1]. The tool is mounted on a CNC machine. A forming tool path is moved accordingly over a clamped blank with step size (vertical feed) $[1,2,3]$. The complicated geometry information is resolved into a series of 2D-dimensional layers, and then the plastic deformation is carried out layer-by-layer through the CNC controlled movements of the forming tool to obtain the desired part [4]. A sketch of ISF types is presented in Fig. 1 [3].

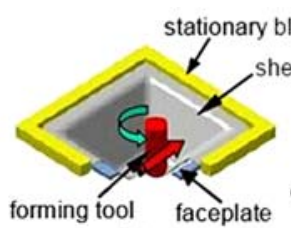

(a)

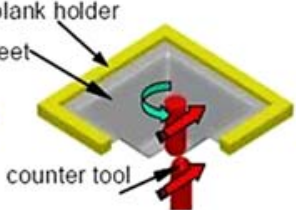

(b)

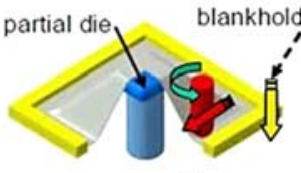

(c)

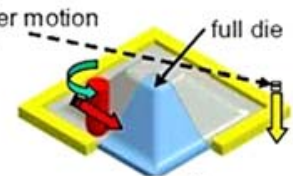

(d)

Fig. 1. Configurations of asymmetrical ISF [3].

The applications of the Single Point Incremental Forming process (SPIF) include production of small quantities or fast prototyping, as it is a highly flexible forming process. Sheet metal parts can be obtained without using special dies [5].

*Corresponding author: Khalil1969a@yahoo.com 
The technology of SPIF has several benefits, which include high flexibility, low costs for hardware and high formability. Complicated geometries can also be obtained through SPIF without using expensive dies. The time to market is also reduced due to the fact that there are no dies needed for the deformation. SPIF could be successfully employed in automobile, aerospace and biomedical industries for prototyping and small-lot productions [6].

The main drawbacks of SPIF are low predictability due to springback, wall angle restraints, thinning of the material and the product surface quality. There have been employed some approaches to reduce the negative effects of the process: warm forming [7], laser assisted heating [8] and electric heating through the tool [9]. The ISF process is influenced by several factors, such as type of tool, use of lubrication, plane anisotropy, feed rate [10].

Two Point Incremental Forming (TPIF) with partial die was introduced [11]. According to the analytical model obtained, the mechanical deformation of SPIF and TPIF are handled. Also, the partial die prevents the formation of neck in TPIF. The parts obtained with partial die by TPIF have higher geometric accuracy than those obtained through SPIF. This can be explained by smaller elastic recovery at loading.

Asymmetric Incremental Sheet Forming (AISF) was mixed with stretch forming to obtain a new hybrid process [12]. Compared to AISF, the new process requires less time, especially when identifying in advance the processed areas. The thickness distribution was more homogenous and the maximum thinning was improved.

The use of different deformation steps on both surfaces in order to test the process selfcapabilities to correct inaccuracies was analyzed [13]. At the second repeated step, the accuracy increases. At new steps, the accuracy is not improved.

This research focuses on using a new type of forming tools movement (upper TPIF) and evaluating the product profile, thickness and strain distribution after usage. Using the simple way to simulation upper TPIF model (2D model), a new type of evaluation was employed chattering status - to observe the behavior of the entire blank surface as a reflection of the forming tool movement. Some of the applications of Aluminum material used are: buildings; roofing, cladding, signage, road signs and furniture.

\section{FE model development}

The FE model was developed to simulate the forming process using ANSYS 11, purpose of linear and nonlinear FEM analysis program. The FE simulation was incorporated into a combined system of sheet metal forming. The model developed to simulate the SPIF process incorporates the effects of contact between the tool set and workpiece. In the FE model, constant forming tool, fixture and blank characteristics were used in order to analyze the effects of pre-forming tool movement, as shown in Fig. 2.

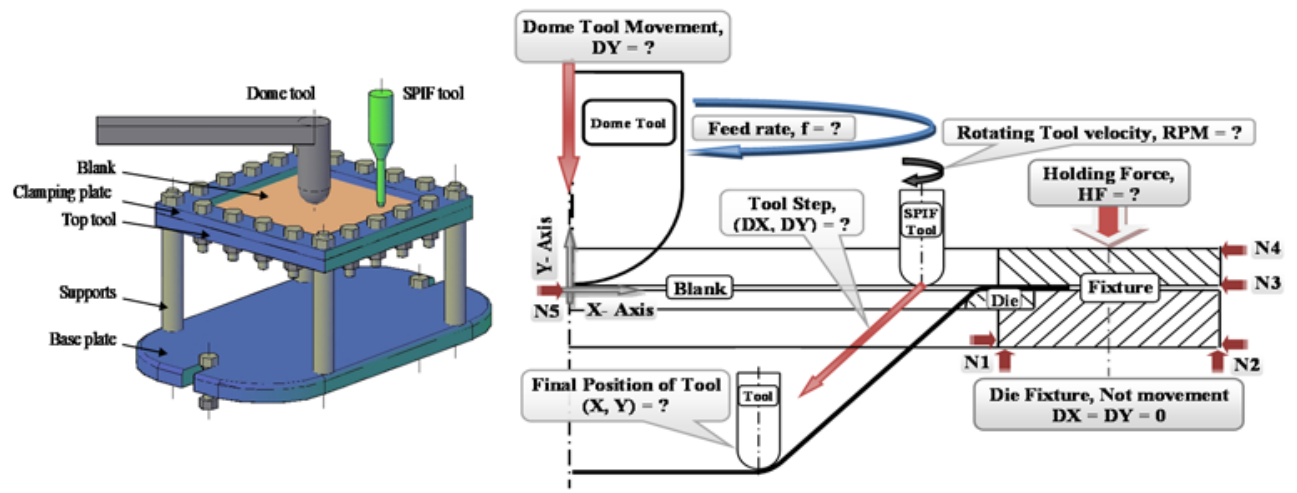

Fig. 2. Basic tools of upper TPIF process and the boundary conditions. 
The blank is represented through a quadrilateral mapped mesh. Fig. 2 presents the boundary conditions - displacement, loading, contact and the forming tool speed was constant.

For the model, the blank type is of $220 \mathrm{~mm}$ outside diameter $(\mathrm{Db})$ and $0.9 \mathrm{~mm}$ thickness $(\mathrm{t})$. The forming tool profile diameter $(\mathrm{Dp})$ is $10 \mathrm{~mm}$, and all six cases are with the same die profile (Dd) of $5 \mathrm{~mm}$. The interface tool-blank is represented with the friction coefficient $(\mu), 0.05$. For the material, Aluminum EN AW 1050 (A199,5) was selected, the specific mechanical properties of a tensile test resulted from load-extension curve are shown in Table 1.

Table 1. Material properties of the blank.

\begin{tabular}{|c|c|c|c|c|c|}
\hline Variable & $\begin{array}{c}\text { Density, } \\
\boldsymbol{\rho}, \mathrm{g} / \mathrm{m}^{3}\end{array}$ & $\begin{array}{c}\text { Young's modulus, } \\
\mathbf{E}, \mathrm{GPa}\end{array}$ & $\begin{array}{c}\text { Poisson's ratio, } \\
\mathbf{v}\end{array}$ & $\begin{array}{c}\text { Yield stress, } \\
\boldsymbol{\sigma}_{\boldsymbol{y}}, \mathrm{MPa}\end{array}$ & $\begin{array}{c}\text { Tangent modules, } \\
\mathbf{E} \boldsymbol{\tau}, \mathrm{GPa}\end{array}$ \\
\hline Value & 2700 & 75 & 0.3 & 80 & 0.5 \\
\hline
\end{tabular}

For the simulation, the element PLANE42-2D was selected to represent the tool set and the element V15C0106-2D to represent the blank, and both have $\mathrm{x}$ and $\mathrm{y}$ translation directions.

The element representing the contact tool set, which includes the forming tool, die and blank holder, is CONTAC169 and for the blank is CONTAC171-2D Point-to-Surface Contact, like a Rigid-to-Flexible contact. The real constant set was used for each contact surface. A non-linear analysis, convergence criteria, incremental load and specified load steps are applied. The convergence tolerance was based on minimization of the force residual.

For the tool path, the CAD model built includes the properties of the product profile, all dimensions related with the fixture parts and the forming tool coordinates.

\section{Results and Discussion}

Five predicted AutoCAD models to produce the product profile with pre-movement in depths, $\mathrm{h}=0,0.2,1,5$ and $10 \mathrm{~mm}$, and the details of the model are presented in the Fig. 3 .

These procedures are used as a primary movement to start producing a new profile of SPIF process with forming tool path movement $50 \mathrm{~mm}$ depth and with $45^{\circ}$ degree.

In Fig. 3 the FEM models of the products are presented. The dome forming tool starts to move vertically on the y-axis to distance h mm (Fig. 3 a-1), followed by the SPIF forming tool according to the tool path profile ( $45^{\circ}$ degree) (Fig. 3 a-2) to be at that time move together until product profile complete (Fig. 3 a-3).

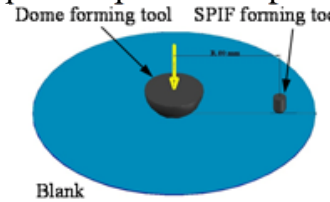

$(\mathrm{a}-1)$

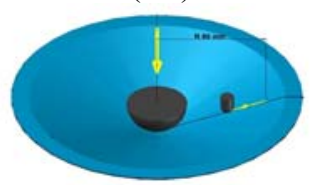

(a-2)

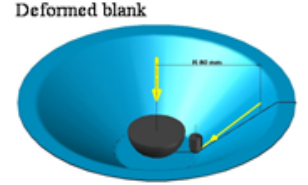

(a-3)

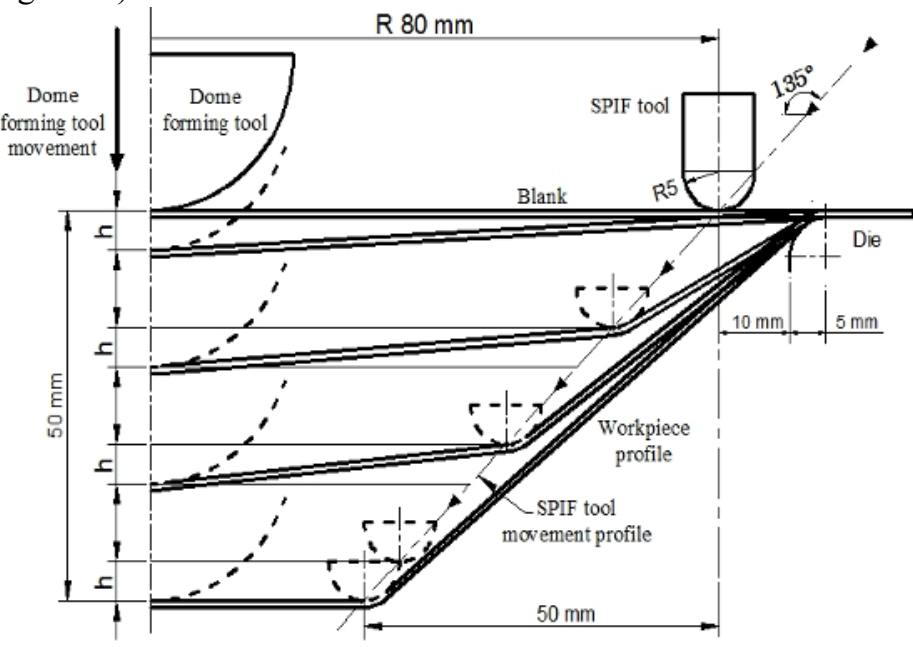

(b)

Fig. 3. Typical forming tool movement profile for dome and SPIF forming tool. 
The thickness distribution evaluation of the upper TPIF deformed product is shown in the Fig.

4. The section of the product is divided into four regions, as follows:

- 100 to $110 \mathrm{~mm}$ from blank center (fixed region), there is not effect of the tool movement;

- 90 to $100 \mathrm{~mm}$ from blank center (backing plate profile effect region), maximum reduction is $0.08 \mathrm{~mm}$ from $0.9 \mathrm{~mm}$ blank thickness, when using $10 \mathrm{~mm}$ h value;

- 40 to $90 \mathrm{~mm}$ from blank center, (SPIF forming tool movement effect region), clear regular reducing in thickness distribution of all $\mathrm{h}$ values;

- 0 to $40 \mathrm{~mm}$ from blank center, (dome forming tool movement effect region), where the thinning decreases with increasing the h value, as illustrated in the Fig. 6.

The results for strain distribution include the strain values for each node of the numerical model and the values of all nodes at each forming tool step size. As a consequence, a very high number of data is included in the final results.

To analyse the effects of pre-forming tool movement, Fig. 5 includes strain distribution for the upper surfaces, for $50 \mathrm{~mm}$ vertical stroke and $45^{\circ}$ angle of forming tool.

The strain peak values are concentrated along the blank section between 0-45 mm distances from the blank center and increase towards the blank center. The strain increases uniformly and the strain values are acceptable at distances $45-100 \mathrm{~mm}$ from the blank center. There is no deformation occurring under the blank holder (100-110 $\mathrm{mm}$ from the blank center).

The maximum strain values are concentrated on the places between the forming tool movements, as well as on the places under the center of the forming tool dome $(0-10 \mathrm{~mm}$ from the blank center). The strain values increase with increasing the $h$ value.

The evaluation of the strains along the deformed blank section is illustrated in the Fig. 6 . The section of the product can be divided into four regions - blank holder, die edge, tool path and between tools. In the first and second regions there is no effect of the forming tool movement, while in the third and the fourth regions the highest strain distributions appear in the areas that are in direct contact or near the forming tool position than others areas along product section.

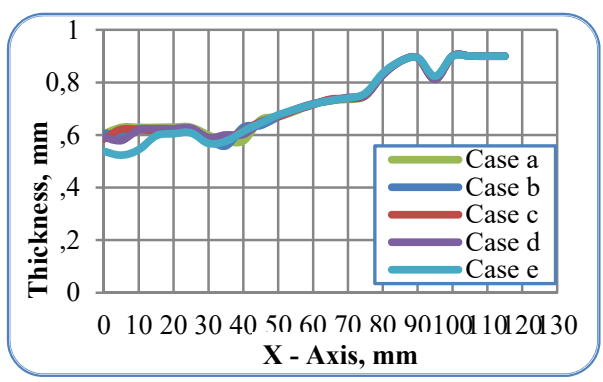

Fig 4. Thickness distribution of different ways.

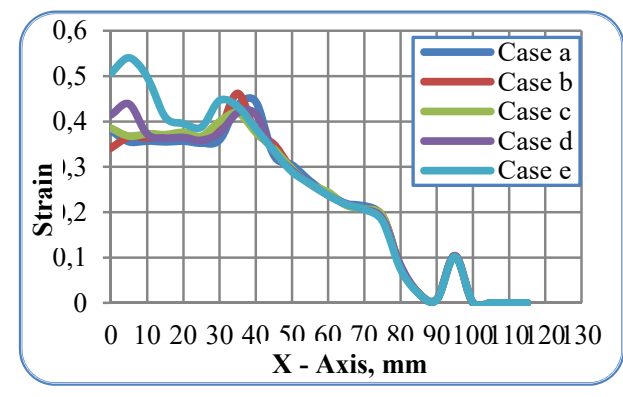

Fig. 5. Strain distribution of different ways.

The strain distributions are concentrating on the zone between $30-50 \mathrm{~mm}$ from the blank center. This is obviously improved on two levels. The first level is to reduce the surface strain on the upper blank surface and on blank section, while the second level is to reduce thinning with increasing the $\mathrm{h}$ value (cases $\mathrm{a}, \mathrm{b}, \mathrm{c}, \mathrm{d}$ and e respectively). At same time, the maximum strain value increased from 0.495 to 0.542 and moved from the zone near the forming tool edge (in case a), to be under the dome tool (in case e) (Fig. 6). Other important notes: the profile of the product is the same in all the cases, which is clearly a good indication that any changes in $h$ value will not affect the product profile resulting from this processing model.

The rotating tool velocity, the constant feed rate along the contour of the product and the support-free wide blank surface produce an operation similar to continuous forming with pulses. The operation is producing a continuous vibration of the blank. The level of vibration is affected by depth of deformation and product shape. Large support-free area and increasing vibration lead to chattering effect as is shown in Fig. 7. 
Successive stages that are used in pre-forming tool movement to produce the SPIF product profile are shown in the Fig. 7. It is clear that the forming tool stroke influences greatly the chattering values, in which these values increase with depth of stroke. The peak height appears to be a good indicator to assess whether a forming operation will be stable or not. The severe of the chattering statuses distribution is located at the positions where the forming tools are.

Six steps, 0.2, 10, 20, 30, 40 and $50 \mathrm{~mm}$ depth, are used to evaluate the chattering statuses during simulation process (Fig. 7). At two positions the chattering appears under SPIF and dome forming tool, where the direct contact occurs.

At the first step, there is no chattering status because of the elastic properties of the blank material. The same situation appears at the end stroke, as well, but because of high tension and reducing the unsupported areas.

Using the dome forming tool caused clear reducing in the chattering statuses at all the steps under the SPIF forming tool, and transfer it to be under the dome forming tool with low levels. That means the dome forming tool absorbed the vibrations, first by reducing the support free-area and giving the blank stability during blank metal deformation by the SPIF forming tool with continuous direct contact between tool and blank.

Evaluating the chattering statuses under the SPIF forming tool in all cases with six steps is represented and detailed in Fig. 8. At the first steps $(0.2 \mathrm{~mm}$ depth) low values were registered and without chattering in cases $\mathrm{d}$ and $\mathrm{e}$, where there is no direct contact because the $h$ value which is higher than the step size.

At step $10 \mathrm{~mm}$ depth, there are no chattering statuses in all cases, and that is a good indication of improving the conditions of the process. At step $20 \mathrm{~mm}$ depth, the chattering values increased at 5 and $10 \mathrm{~mm}$ h values, slightly decreased at the step $30 \mathrm{~mm}$ depth and at $10 \mathrm{~mm}$ h value very low chattering values were recorded.

Chattering values levels continued to decrease during the step $40 \mathrm{~mm}$ depth with all $\mathrm{h}$ values, as well as until the latest step $50 \mathrm{~mm}$ depth of all $\mathrm{h}$ values. Depending on the chattering statuses, increasing the $\mathrm{h}$ value with more than $1 \mathrm{~mm}$ depth makes the process more stable, especially at the SPIF forming tool position.

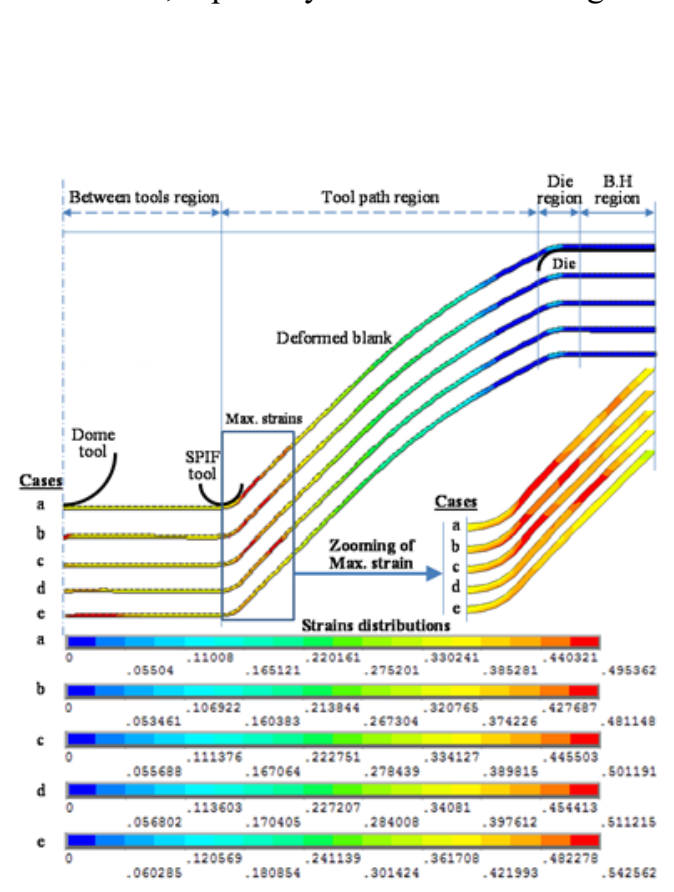

Fig. 6. Strain distribution of deformed products.

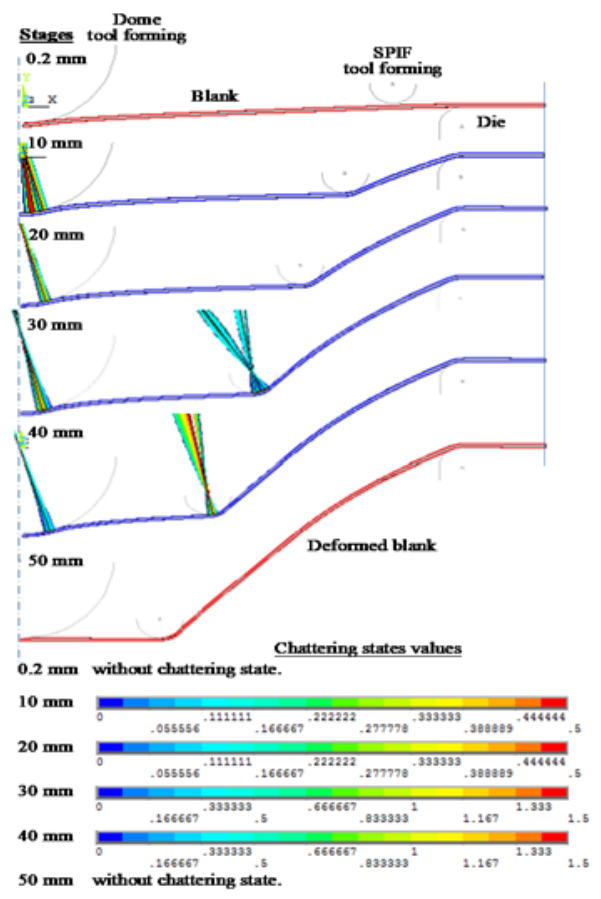

Fig. 7. Chattering statuses behavior of case $d$. 


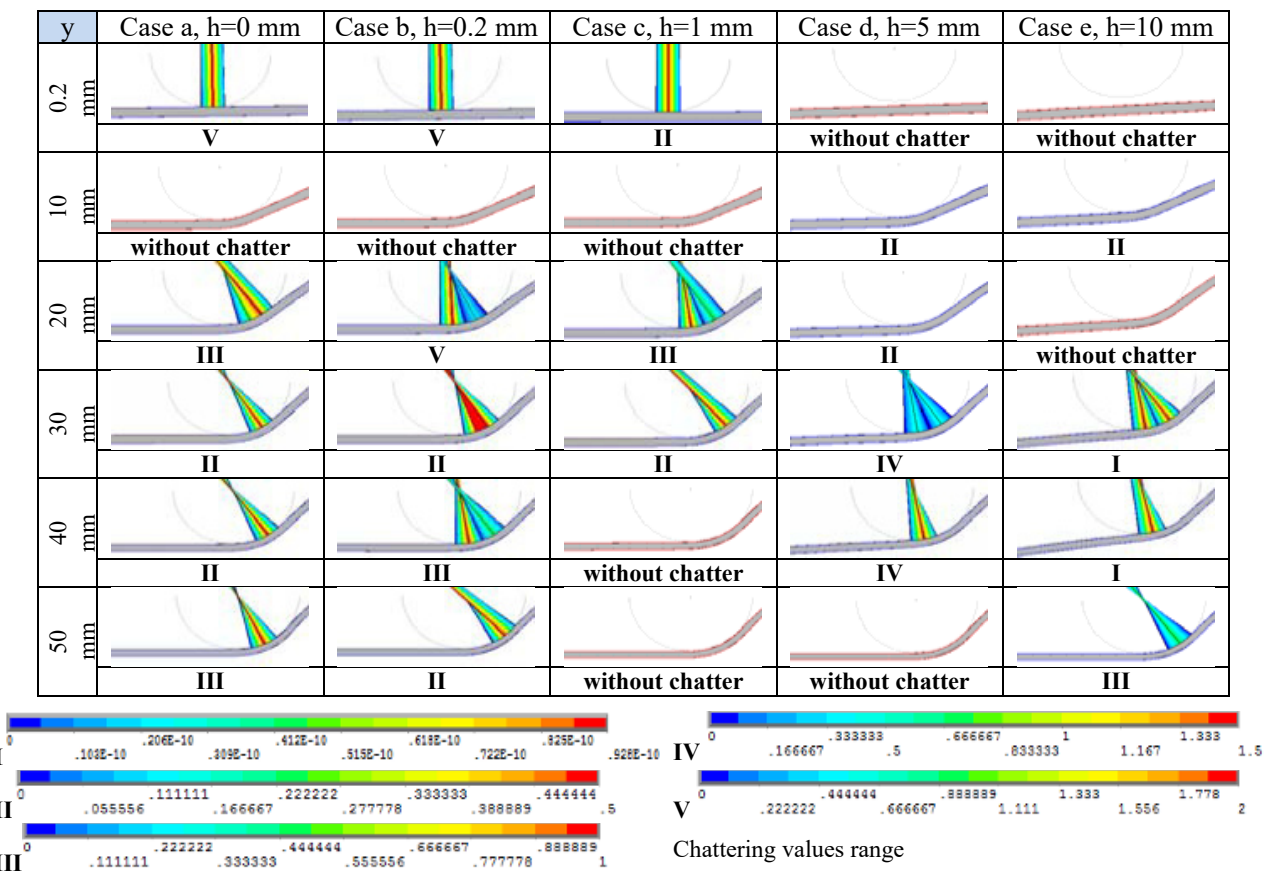

Fig. 8. Chattering statuses behavior at SPIF forming tool.

\section{Conclusions}

The 2D simulation model of ISF by FEM with pre-forming tool movement (upper TPIF) can predict an ideal profile of processing trajectory. The high values of strain distributions along the section of the product profile appear to be good indicators to assess whether a product will be successful or not. The results also showed improvement in the strain distributions along the deformed blank section by using upper TPIF process.

Based on the chattering statuses evaluations the upper TPIF process appears to be more stable during the deformation process steps than traditional SPIF.

In addition, decreasing the chattering statuses means reducing the pulses, keeping continuously deformation contact tool-blank and reducing the surface roughness.

\section{References}

1. J. Kopac, Z. Kampus, J. of mate. Pro. techno., 162-163 622-628 (2005)

2. A. Hadoush, A. H. van den Boogaard, Int. J. Mater. Form. 2 pp 181-189 (2009)

3. U. Khare, M. Pandagale, ICAET-2014, IOSR J. Mech. Civil Eng. PP $42-46$ (2014)

4. R. P. Singh, G. Goyal, Int. J. Eng. Research and Applications (IJERA) pp 33-37 (2014)

5. R. Benmessaoud, Int. J. Adv. Research in Comp. Sci. and Soft. Eng. 4 pp 1035-1044 (2014)

6. M. A. Dittrich, T. G. Gutowski, J. Cao, Prod. Eng. Res. Devel. 6 pp 169-177 (2012)

7. G. Ambrogio, L. Filice, G. L. Manco, CIRP Annal - Manuf. Tehcn. 571 pp 257-260 (2008)

8. J. R. Duflou et al, Int. J. Mach. Tools and Manufacture 485 pp 543-549 (2008)

9. F. Guoqiang, S. Fentao, M. Xiangguo, Int. J. Adv. Manuf.Techno. 499 pp 941-947 (2010)

10. J. Sheoran, I. Monga, Int. J. for Tech. Res.In Eng. 2, 8, pp 1365-1368 (2015)

11. M. B. Silva, P. A. F. Martins, JMEPEG 22 pp 1018-1027 (2013)

12. B. T. Araghi, G. L. Manco, M. Bambach, CIRP Annals-Manuf. Techno. 58 pp 225-228 (2009)

13. G. Ambrogio, L. Filice, Int. J. Mate. Form. 5 pp 269-274 (2012) 